\title{
Delusional parasitosis heralding the diagnosis of peripheral neuropathy
}

\author{
Delírio de parasitose como precursor do diagnóstico de neuropatia periférica \\ Paulo Marcelo Gondim Sales ${ }^{1}$, Florian Patrick Thomas², Francisco de Assis Aquino Gondim¹,3 \\ 1 Universidade Federal do Ceará, Fortaleza CE, Brazil; \\ ${ }^{2}$ Department of Neurology and Psychiatry, Saint Louis University; \\ ${ }^{3}$ Medical School Christus, Fortaleza CE, Brazil. \\ Correspondence: Francisco Gondim; Faculdade de Medicina Christus; Rua João Adolfo Gurgel 133; 60190-060 Fortaleza CE - Brasil; \\ E-mail:gondimfranc@yahoo.com \\ Conflict of interest: There is no conflict of interest to declare. \\ Received 03 March 2012; Received in final form 19 July 2012; Accepted 26 July 2012
}

The term "delusional parasitosis" (Ekbom syndrome) has been used to describe a group of rare neuropsychiatric disorders characterized by the recurrent delusional belief that one's body is being invaded by parasites, insects or small animals ${ }^{1}$.

We present a case of delusional parasitosis heralding the diagnosis of peripheral neuropathy (PN). A 77 year-old woman with no significant past medical history presented with generalized dysesthesias, more prominent over the cervical area and head (parietal area), which began since she started to drink an extract oil of Copaiba (Copaifera spp) mixed with honey. After a few months, she developed strange sensations, as if "insects were moving and leaving" her head and body. She insisted that the oil she had ingested contained larvae of insects and, once they grew up, they invaded her head and body. She was seen by several different physicians and lost 
$18 \mathrm{~kg}$ over a few months. Six months prior to our evaluation she developed bilateral foot numbness, insomnia and dry mouth. She denied autonomic disorders and family history of similar problems or PN.

Her neurological examination revealed normal mental status and cranial nerve examination; mildly decreased motor strength in the distal upper and lower extremities with atrophy of bilateral abductor pollicis brevis; bilateral Tinel's sign on the wrist; generalized hyporreflexia; decreased pin in a stocking and glove and bilateral distal median nerve distribution on the hands; normal vibration, coordination and gait, including ability to walk on heels and tip toes; negative Romberg's test.

Gabapentin (300 mg daily and then twice a day) led to minor improvement. Table details the results of nerve conduction studies and electromyography: distal symmetric sensorimotor axonal PN with superimposed bilateral median neuropathy at the wrist. Laboratory evaluation did not disclose PN etiology (normal glucose tolerance test, AST, ALT, BUN, creatinine, $\mathrm{LDH}$, serum cholesterol, triglycerides, Rheumatoid Factor, Antinuclear Antibodies, TSH, T4, Anti-SSA and SSB, HbsAg, hepatitis C titer, Ca-125, folic acid and B12 levels; CEA was slightly elevated, hemoglobin was $10.2 \mathrm{~g} / \mathrm{dl}$, hematocrit $33.1 \%$ and ESR was $38 \mathrm{~mm}$ ). Additional tests were ordered, but she missed her follow-up appointment.

Our patient had all the classical features of delusional parasitosis, including being a female and elder. She was also possibly suffering from a depressive or adjustment disorder, since she had recently moved from a different city, but denied significant psychiatric history or cognitive impairment.
Table. Description of electrodiagnostic findings in the case report of delusional parasitosis heralding the diagnosis of peripheral neuropathy. Abnormal values are displayed in bold.

\begin{tabular}{|c|c|c|c|c|}
\hline \multicolumn{5}{|l|}{ Motor } \\
\hline Nerve & $\mathrm{DL}$ & Amp & $\mathrm{CV}$ & $\mathrm{F}$ \\
\hline R/L Tibial & $4.4 / 5.1$ & $3.3 / 5.1$ & 51 & $49.2 / 53.8$ \\
\hline R/L Peroneal & $4.4 / 3.9$ & $1.1 / 1.5$ & $50.1 / 51.3$ & $56.9 / 59.3$ \\
\hline R/L Median & $6.0 / 5.2$ & $1.9 / 2.0$ & 51.3 & 32.3 \\
\hline R Ulnar & 2.5 & 6.8 & 46.6 & 28.8 \\
\hline \multicolumn{5}{|l|}{ Sensory } \\
\hline $\begin{array}{l}\text { L Median } \\
\text { (Orthodromic)* }\end{array}$ & 3.9 & 2.2 & 40.2 & \\
\hline
\end{tabular}

Absent bilateral sural and right median sensory (orthodromic) responses Electromyography:

Fibrillations and positive sharp waves on bilateral tibialis anterior and right gastrocnemius with increased proportion of polyphasic potentials

DL: Distal onset Latency (ms); Amp: Distal Amplitude, CMAP for motor ( $m V$ ) and SNAP for sensory studies $(\mu \mathrm{V})$; CV: Conduction Velocity $(\mathrm{m} / \mathrm{s})$; L: left; ortho: orthodromic; R: right; *Left Median (Ring electrode Stimulation); F: FWave (ms).

Delusional parasitosis has been linked to neurocysticercosis, strokes, dementia, vitamin B12 deficiency, diabetic neuropathy and leprosy ${ }^{2-4}$. It is unlikely that the extract oil of Copaiba (Copaifera spp) had anything to do with her symptoms. This extract is widely used by the folk medicine in several parts of Brazil due to its anti-inflammatory and antinociceptive properties ${ }^{5}$. In all the prior reports of delusional parasitosis, no details about the PN phenotype or electrodiagnostic tests were disclosed. Therefore, our case report is the first to describe the electrodiagnostic findings of a classic PN length-dependent axonal sensorimotor. A thorough neurological examination was helpful to raise the possibility of PN despite the delusional and unreliable symptom description.

\section{References}

1. Ramirez-Bermudez J, Espinola-Nadurille M, Loza-Taylor N. Delusional parasitosis in neurological patients. Gen Hosp Psychiatry 2010;32:294-299.

2. Hinkle NC. Ekbom syndrome: the challenge of "invisible bug" infestations. Annu Rev Entomol 2010;55:77-94.

3. Trabert W. 100 years of delusional parasitosis. Meta-analysis of 1,223 case reports. Psychopathology 1995;28:238-246.
4. Boggild AK, Nicks BA, Yen L, et al. Delusional parasitosis: six-year experience with 23 consecutive cases at an academic medical center. Int J Infect Dis 2010;14:317-321.

5. Gomes NM, Rezende CM, Fontes SP, Matheus ME, Fernandes PD. Antinociceptive activity of Amazonian Copaiba oils.J Ethnopharmacol 2007;109:486-492. 